\title{
Tünel Projelerinde Harita Mühendisliği Uygulamaları: Yeni Zigana Tüneli Örneği
}

\author{
Geomatics Engineering Applications in Tunnel Projects: New Zigana Tunnel Case
}

\author{
Fatih DÖNER ${ }^{* 1, a}$, Erdal KÖSE ${ }^{2, b}$ \\ ${ }^{1}$ Gümüşhane Üniversitesi, Mühendislik ve Doğa Bilimleri Fakültesi, Harita Mühendisliği Bölümü, 29100, Gümüşhane \\ ${ }^{2}$ Rize Kadastro Müdürlüğ̈̈, Pazar Birimi, 53300, Rize
}

\begin{tabular}{|c|c|c|}
\hline - Geliș tarihi / Received: 21.05 .2020 & - Düzeltilerek geliş tarihi / Received in revised form: 06.08.2020 & - Kabul tarihi / Accepted: 12.08 .2020 \\
\hline
\end{tabular}

\begin{abstract}
Öz
$\mathrm{Bu}$ çalışmada, Yeni Zigana Tüneli (YZT) projesindeki harita mühendisliği uygulamaları teknik ve hukuki işler olmak üzere iki bölüme ayrılarak incelenmektedir. Çalışmada, YZT projesinin inşaat aşaması öncesindeki harita mühendisliği alanını ilgilendiren teknik işleri yer kontrol noktaları tesisi, jeodezik referans sistemi seçimi, yükseklik sistemi ve jeoit modeli seçimi, harita projeksiyonu seçimi, koordinat dönüşümü ve halihazır harita üretimi olarak gruplandırılarak incelenmiş̧ir. YZT projesindeki hukuki işler ise kamulaş̧ırma ve taşınmaz değerleme faaliyetleri olarak ele alınarak değerlendirilmiştir. Gelişen ölçme teknoloji sayesinde yersel ve uydu bazlı teknikler kullanılarak tünel projesinin uygulanması için ihtiyaç duyulan harita bilgileri üretilebilmiştir. Yoğun bitki örtüsü ve elverişsiz topografya şartları zaman zaman GNSS kullanımı engellemiştir. GNSS ile belirlenen elipsoit yükseklikleri yanında, geometrik nivelman ile ortometrik yükseklikler de belirlenmiştir. Hukuki işlerde karşılaşılan temel problemler ise kamulaştırma çalışmalarının uzun sürmesi ve kıymet takdir komisyonu tarafından belirlenen, taşınmaz maliklerine ödenecek bedelin çoğu durumda gerçek değeri yansıtmaması nedeniyle maliklerle uzlaşma sağlanamamasıdır. İki boyutlu kadastro parsellerini ve bu parseller üzerindeki hakları tescil etmeyi amaçlayan mevcut kadastro sisteminin parsellerin altından veya üstünden geçen nesnelerin (tünel, enerji nakil hattı gibi) de teknik ve hukuki bilgilerini yönetebilecek şekilde üç boyutlu bir yapıya kavuşması projelerin uygulanmasında yaşanan problemleri en aza indirecektir.
\end{abstract}

Anahtar kelimeler: GNSS, Kamulaştırma, Nivelman, Taşınmaz Değerleme, Yeni Zigana Tüneli

\begin{abstract}
In this study, geomatics engineering applications of New Zigana Tunnel (NZT) project are divided and examined into two parts as technical and legal works. In the study, technical works related to the field of geomatics engineering prior to the construction phase of the NZT project are examined by grouping them as establishment of ground control points, selection of geodetic reference system, definition of height system and geoid model, selection of map projection, coordinate transformation and map production. Also, the legal works in the NZT project are evaluated as expropriation and real estate valuation activities. Thanks to the developing surveying technology, the map information needed for the implementation of the tunnel project was able to be produced using terrestrial and satellite based surveying techniques. Sometimes, dense vegetation and unfavourable topography conditions prevented the use of GNSS. In addition to the ellipsoid heights determined by GNSS, orthometric heights were determined by geometric levelling. The main problems faced in legal works are that the expropriation works take a long time and the consensus cannot be reached with the owners because the price to be paid to the property owners does not reflect the real value in most cases. To minimize the problems faced current cadastral system, which aims registering two dimensional parcels and rights on these parcels, needs to be converted to a three dimensional structure that enables management of technical and legal information of objects located under or above (tunnel, power transmission line etc.) the cadastral parcels.
\end{abstract}

Keywords: GNSS, Expropriation, Leveling, Real Estate Valuation, New Zigana Tunnel

\footnotetext{
*a Fatih DÖNER; fatihdoner@gumushane.edu.tr, Tel: (0456) 23317 65, orcid.org/0000-0002-3620-5687

${ }^{\mathrm{b}}$ orcid.org/0000-0003-2523-7787
} 


\section{Giriş}

Tüneller, çeşitli kullanım amaçları doğrultusunda yeraltında ya da su altında açılan belli bir geometriye sahip etrafi kapalı mühendislik yapılarıdır. Tüneller kullanım amaçlarına bağlı olarak karayolu tüneli, demir yolu tüneli, metro tüneli, yaya tüneli, su tüneli, atık su tüneli, maden tüneli, parçacık hızlandırıcı tünel gibi isimlerle isimlendirilebilirler (Ademoğlu, 2008). Misirlılar ve Romalılar zamanında su getirmek amaciyla ilk tünellerin açıldığı bilinmektedir. Ulaşım alanındaki ilk tünel örnekleri ise 1863 yılında hizmete giren Londra Metrosu için açılan tünel ve 1875 yılında kullanıma açılan 573 metre uzunluğundaki Taksim-Karaköy tünelidir (Eren, 2014). Ulaşım amaçlı planlanan ve hayata geçirilen yer altı tünel projelerinin sayıları dünyada ve ülkemizde giderek artmaktadır (Tablo 1). $\mathrm{Bu}$ artışın temel nedenleri topografyanın tünel dışındaki çözümlere imkân tanımaması, zorlu iklim koşulları, taşınmazların yüksek kamulaştırma maliyetleri, yer üstünde bulunan korunması gereken yapı veya alanların çokluğu ve sürekli gelişen inşaat teknolojisi sayesinde tünel açmanın geçmişe kıyasla daha kolay hale gelmesi olarak siralanabilir (Broere, 2016).

Tablo 1. Türkiye'deki ulaşım amaçlı bazı tünel projeleri ve tünel uzunlukları

\begin{tabular}{lcc}
\hline $\begin{array}{c}\text { Tünel Projesi } \\
\text { Adı }\end{array}$ & $\begin{array}{c}\text { Uzunluk } \\
\text { (metre) }\end{array}$ & $\begin{array}{c}\text { Tamamlanma } \\
\text { Yılı }\end{array}$ \\
\hline $\begin{array}{l}\text { Yeni Zigana } \\
\text { Tüneli }\end{array}$ & 14481 & Devam ediyor \\
$\begin{array}{l}\text { Ovit Dağı } \\
\text { Tüneli }\end{array}$ & 14000 & 2018 \\
$\begin{array}{l}\text { Kop Dağ } \\
\text { Tüneli }\end{array}$ & 6500 & Devam ediyor \\
$\begin{array}{l}\text { Sabuncubeli } \\
\text { Tüneli } \\
\text { Avrasya }\end{array}$ & 6480 & 2018 \\
$\begin{array}{l}\text { Tüneli } \\
\text { Ilgaz Dağ1 }\end{array}$ & 5400 & 2016 \\
$\begin{array}{l}\text { Tüneli } \\
\text { Cankurtaran }\end{array}$ & 5391 & 2016 \\
Tüneli & 5228 & 2018 \\
\hline
\end{tabular}

Tünel projelerinin hayata geçirmesinde, harita mühendisliği faaliyet alanında bulunan işler teknik ve hukuki olmak üzere iki grupta ele alınabilir. Teknik işler tünel projesinin planlanması, uygulanması ve inşaat sonrası izlenmesi için ihtiyaç duyulan konum bilgilerinin üretilmesi ile ilgiliyken hukuki işler tünel için ihtiyaç duyulan mekânın mülkiyetinin kazanılması ve sınırlı ayni hak tesisi süreçlerini içermektedir.
Bugüne kadar Türkiye'de ve dünyada pek çok çalışmada seçilen tünel projeleri için bu teknik ve hukuki işler ayrı ayrı ele alınmıştır.

Ünlütepe ve Messing (2005)'te tünel projelerinde tünel kazıklarının yönlendirilmesi, tünel giriş yapılarının (şaft, portal) inşası ve deformasyonlarm izlenmesinde kullanılabilecek ölçme teknikleri açıklanmıştır. Kalkan vd. (2005)'te, Üsküdar-Ümraniye II. Etap metro projesi için yatay ve düşey kontrol ağının oluşturulması amacıyla gerçekleştirilen ölçme işleri değerlendirilmiştir. Yalçınkaya vd. (2006)'da Trabzon Şehir Geçiş Tüneli projesinde tünel deformasyonları jeodezik ve geoteknik yöntemlerle izlenmiştir. Satır (2007)'de, Karadeniz Sahil Yolu üzerinde seçilen iki örnek tünel için sonlu elemanlar yöntemiyle tünel deformasyonları tespit edilmiştir. Lee (2007)'de, TBM (Tünel Delme Makinesi - Tunnel Boring Machine) yöntemiyle inşa edilen $7.5 \mathrm{~km}$ uzunluğundaki bir tünel projesi için TBM'nın yönlendirilmesinde gerekli olan ölçme çalışmaları incelenmiştir. Ademoğlu (2008)'de, İstanbul'da NATM (Yeni Avusturya Tünel Açma Metodu New Australian Tunnelling Method) ve TBM teknikleriyle inşa edilen metro tünelleri için gerçekleştirilen jeodezik çalışmalar araştırılmıştır. Seydanlıoğlu (2009)'da, 4.Levent-Ayazağa metro inşaatında, tüneldeki düşey ve yatay deformasyonlar belirlenmiştir. Gengeç (2010)'da, tünel kazılarının yönlendirilmesindeki yatay doğruluk araştırılmıştır. Eren (2014)'te, İstanbul'daki M5 metro projesi için düşey deformasyonun belirlenmesi gerçekleştirilmiştir. Jensen ve Almholt (2015)'te, Almanya ve Danimarka arasında inşa edilen hem karayolu hem de raylı ulaşım için planlanan $18 \mathrm{~km}$ uzunluğundaki Fehmarnbelt tüneli projesindeki jeodezik altyapı çalışmaları incelenmiştir. Li ve Huang (2018)'de, Hong Kong'da inşa edilmekte olan $6.7 \mathrm{~km}$ uzunluğundaki tünel projesi için jeodezik kontrol ağının tesisi ve ölçülmesi çalışmaları açıklanmıştır. Yüceses (2019)'da, Çanakkale ilinde seçilen bir tünel projesi için jeodezik ve geoteknik yöntemlerle deformasyon analizi gerekleştirilmiştir. Faslak (2019)'da, Karayolu tünel inşaatındaki jeodezik çalışmalar Denizli Honaz tüneli örneği üzerinden incelenmiştir.

Karataş vd. (2007)'de, Trabzon Şehir Geçiş Tüneli projesinde mülkiyet problemlerinin çözülmesi süreci değerlendirilmiştir. Tanrıvermiş vd. (2008)'de, Konya ilindeki Mavi Tünel Projesi için kamulaştırma alanındaki arazilerin değerlerinin belirlenmesine yönelik bir çalışma 
gerçekleştirilmiştir.

Balc1

(2010)'da, kamulaştırma maliyetinin ulaşım yatırımları üzerindeki etkisi, İstanbul'da seçilen bir tünel projesi ve bağlantı yolları örneğinde incelenmiştir. Hunt vd. (2014) ve Sun vd., (2017)'de, sirasiyla İngiltere ve Çin'de altyapı tesislerinin geçirilmesi için gerekli olan tünellerin inşasında kazı maliyetinin düşürülmesi için çok amaçlı kullanılabilecek tünel tasarımları önerilmiştir. Hiironen vd. (2015)'de, Helsinki'de (Finlandiya) inşası tamamlanan metro projesinin taşınmazların kira ve satış değerleri üzerine etkisi araştırılmıştır. Kaliampakos vd. (2016)'da, dünya genelinde seçilen bazı tünel projeleri için maliyet-fayda analizi yapılmıştır. Ho ve Rajabifard (2016)'da, Singapur'da kadastro parsellerinin altından ve üstünden geçen nesne bilgilerinin yönetimi için 3B bir arazi idaresi sistemi önerilmiştir. Besner (2017)'de, tünellerle ilgili uluslararası organizasyonlar ve bunların faaliyetleri incelenerek yeraltındaki mekânın tüneller için planlanmasinda daha fazla insan odaklı çözümlerin araştırılması gerektiği belirtilmiştir. Wang vd. (2018)'de, 1959-2020 y1llar1 arasinda Çin'de tamamlanan ve yapımı planlanan altyapı tesisi tünelleri için sorumlu kurumlar, finansman ve kullanım amacı gibi kriterlere göre analizler gerçekleştirilmiştir. Namlı (2018)'de, bir metro hattı tünel projesinde yapılan değişikliğin projenin maliyetine ve tamamlanma süresine etkisi değerlendirilmiştir.

Türkiye'de, mevcut durumda toplamda $357 \mathrm{~km}$ uzunlukta 317 olan karayolu ulaşım tüneli sayısının 2023 yılına kadar $700 \mathrm{~km}$ uzunluğa ve 470 tünele ulaşması planlanmaktadır (KGM, 2019). Çok sayıda çalışmaya rağmen tünel projelerinin harita mühendisliği alanındaki teknik ve hukuki işlerinin bir arada değerlendirildiği çalışmalara ihtiyaç bulunmaktadır. Çalışmanın ikinci bölümünde materyal ve yöntem tanıtılmaktadır. Üçüncü ve dördüncü bölümde, Yeni Zigana Tüneli (YZT) projesindeki harita mühendisliği faaliyetleri sırasıyla, teknik ve hukuki işler olarak değerlendirilmektedir. Çalışma sonuç bölümüyle sona ermektedir.

\section{Materyal ve Yöntem}

$\mathrm{Bu}$ çalışmada, kapsamlı bir literatür araştırması ardından seçilen bir tünel projesi için harita mühendisliği faaliyetlerinin değerlendirilmesi yöntemi benimsenmiştir. Harita mühendisliği faaliyetleri Şekil 1'de gösterildiği gibi teknik ve hukuki işler olarak iki gruba ayrılarak her bir gruptaki alt faaliyetler belirlenmiştir. Çalışma için seçilen proje YZT projesidir.

\section{YZT Harita Mühendisliği Uygulamaları}

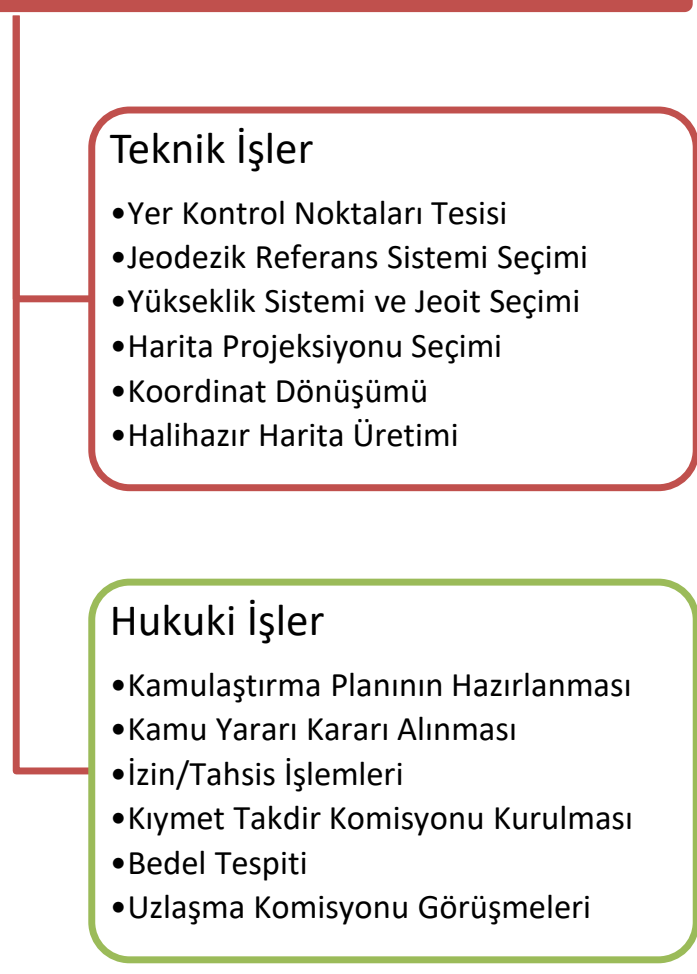

Şekil 1. YZT Harita mühendisliği uygulamaları

13 Mart 2017 tarihinde temeli atılan ve halen yapımı devam eden YZT projesi, her biri 14.5 kilometre olan toplam 29 kilometre uzunluğundaki çift tünel tüpü ile Türkiye ve Avrupa'nın birinci, dünyanın ikinci en büyük karayolu ulaşım tüneli projesi olarak kabul edilmektedir. Tarihi İpek Yolu güzergâhı üzerinde yapımı süren proje kapsamında, Gümüşhane'nin Torul ilçesine bağlı Köstere köyü mevkii ile Trabzon'un Maçka ilçesine bağlı Başarköy köyü arasında her biri 14,5 kilometre uzunluğunda çift tünel inşa edilecektir (Şekil 2). YZT projesiyle, Başarköy Vadisi'nden 1015 metre kotu ile tünele girilip, 1264 metre kotuna kadar yüzde 3.30 eğimle ulaş1ldıktan sonra, yüzde 0.85 eğimle inişe geçilerek Köstere Vadisi'nden 1212 metre kotu ile tünelden çıkmak suretiyle Zigana Dağı'nın geçilmesi planlanmaktadır. $\mathrm{Bu}$ sayede, mevcut Zigana Tüneli'ne göre, YZT ile yaklaşık 530 metre daha düşük kottan geçilerek Zigana Dağ1 aşılabilecektir (Şekil 3). YZT, TrabzonGümüşhane arasındaki yol güzergâhı uzunluğunu $8 \mathrm{~km}$ kısaltması yanında, kış aylarındaki zorlu iklim koşulları ve heyelan nedeniyle tehlikeli olan mevcut ulaşımın daha güvenli ve konforlu bir şekilde gerçekleştirilmesine de imkân sağlayacaktır. Ayrıca, YZT ile mevcut durumda yaklaşık 1.5 saat olan Trabzon-Gümüşhane illeri 
arasındaki ulaşım süresi 1 saatin altına düşerek ulaşım süresi ve yakıt maliyetinde tasarruf sağlanacaktır. YZT teknik işleri Cengiz İnşaat Sanayi ve Ticaret A.Ş. tarafindan yürütülürken, hukuki işler ise Karayolları Genel Müdürlüğü (KGM) Kamulaştırma Dairesi sorumluluğunda yürütülmektedir.

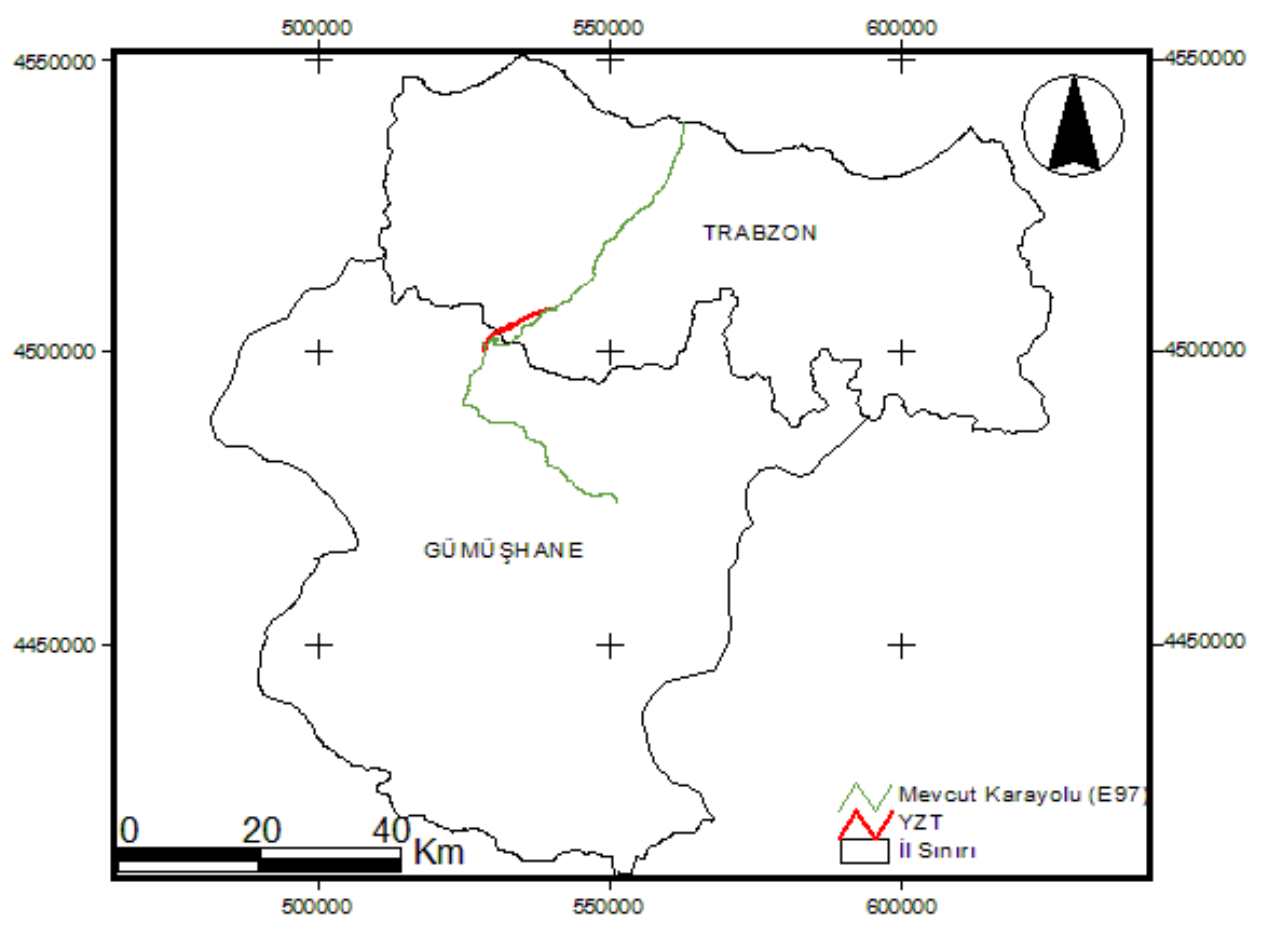

Şekil 2. YZT projesi güzergâh1

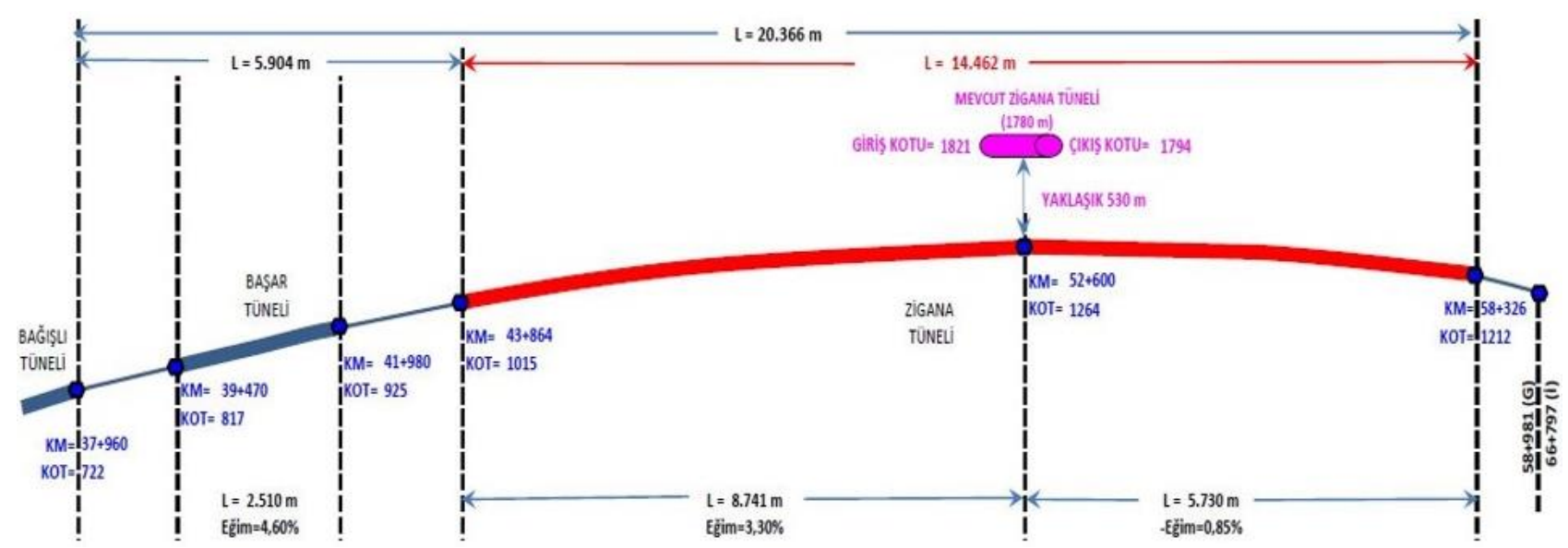

Şekil 3. YZT projesi tünel giriş ve çıkış noktalarının yükseklikleri

\section{YZT Projesi Teknik İşleri}

YZT projesi için tesis edilen temel yer kontrol noktaları tünel giriş ve çıkış bölgesinde yer alan altışar adet beton pilyeden oluşmaktadır. Bunlara ek olarak, çalışma alanında bulunan daha önce tesis edilmiş dört yer kontrol noktası (nirengi) daha kullanılmıştır. Ölçme aletlerinin düzeçlenmesi için pilyeler üzerinde sabit yükseklikli bağlantı sehpalarından (tribrach) yararlanılmıştır. Yer kontrol noktalarındaki ölçme işleri iki ayrı ölçü ekibi tarafından eş zamanlı olarak gerçekleştirilmiştir. Yer kontrol noktalarının konumları GNSS (Global Navigation Satellite Systems-Küresel Seyrüsefer Uydu Sistemleri) ölçü tekniğiyle belirlenmiş̧tir. Bunun yanında, hassas (geometrik) nivelman ölçü tekniği ve invar miralar kullanılarak yer kontrol noktalarının ortometrik yükseklikleri belirlenmiştir. Yer kontrol noktaları projedeki tüm ölçme çalışmalarının dayanağı olacağından bu noktalarının yatay ve düşey konumları periyodik ölçümlerle izlenerek bir deformasyon olup olmadığı kontrol edilmektedir. Yer kontrol 
noktalarının isimlendirilmesi 26.06.2018 tarih ve 30460 sayılı resmi gazetede yayımlanan Büyük Ölçekli Harita ve Harita Bilgileri Üretim Yönetmeliği (BÖHHBÜY)'nin 8.maddesine göre yapılmaktadır. Buna göre, A derece ağlar ve noktalar, Global (ITRF, WGS84) ve bölgesel (ETRF) ağlar ve noktaları, B derece ağlar, uluslararası veya bölgesel ağlara dayalı Türkiye Ulusal Temel GPS Ağı (TUTGA) noktalarını, C derece ağlar, B derece ağın sıklaştırılması ile oluşan ağları ifade etmektedir. $\mathrm{C}$ dereceli ağların alt dereceleri ise baz uzunluğuna göre belirlenmektedir. Buna göre baz uzunluğu 15-20 $\mathrm{km}$ olan ăg ve noktalar $\mathrm{C} 1$, ortalama kenar uzunluğu $5 \mathrm{~km}$ olan ağ ve noktalar $\mathrm{C} 2$, en büyük baz uzunluğu $3 \mathrm{~km}$ olan ağ ve noktalar $\mathrm{C} 3$ ve poligon noktaları C4 olarak adlandırılmaktadır. Türkiye Yatay Kontrol Ağı'na dayalı olarak yersel tekniklerle üretilen noktalar nirengi noktalarını ve Türkiye Ulusal Düşey Kontrol Ağı'na dayalı olarak üretilen noktalar ise nivelman noktalarını oluşturmaktadır. YZT projesi için tesis edilen yer kontrol noktalar1 16 adet nirengi, 16 adet $\mathrm{C} 1$ ve 25 adet $\mathrm{C} 4$ noktasından oluşmaktadır.

YZT projesinde ITRF96 (International Terrestrial Reference Frame 1996-Uluslararas1 Yersel Referans Çerçevesi-1996 yılında güncellenmiş
ITRF) jeodezik referans sistemi esas alınmıştır. ITRF, nokta koordinatları ve noktaların hareket hızlarının, yerkabuğundaki tüm plakaların hareket ettiği varsayılan bir modele göre belirlenen dinamik bir ağdır. Ölçme işlerinde ülke nirengi ve nivelman ağındaki deformasyonları yok edebilmek aynı zamanda GNSS teknolojilerden en fazla düzeyde faydalanabilmek için ITRF sistemi tercih edilmektedir (Ayhan vd., 1999). ITRF kullanılmasının bir diğer avantajı da diğer kurumların projelerinin YZT projesi ile ilişkilendirilmesinde kolaylık sağlayacak olmasıdır. $\mathrm{Bu}$ nedenle, YZT projesi için tesis edilen jeodezik noktaların koordinatları TUTGA'ya dayalı olarak ITRF datumunda elde edilmiştir. TUTGA, savunma ve kalkınma amaçlarına yönelik olarak tüm kullanıcıların duyarlı konum gereksinimlerini karşılamak üzere uydu tekniklerine dayalı ve 1997-2001 yıllarındaki çalışmalarla kurulmuştur. 1997 y1lında 296, 1998 y1linda 207 ve 1999 yilinda ise 91 adet TUTGA noktası tesis edilmiştir. TUTGA; konumları yer küre üzerinde $1-3 \mathrm{~cm}$ doğruluğunda bilinen sürekli güncellenen yaklaşı 700 noktadan oluşmaktadır (HGM, 2020). Şekil 4'te YZT projesi yatay kontrol ağ1 TUTGA bağlant1 noktalarıyla birlikte gösterilmektedir.

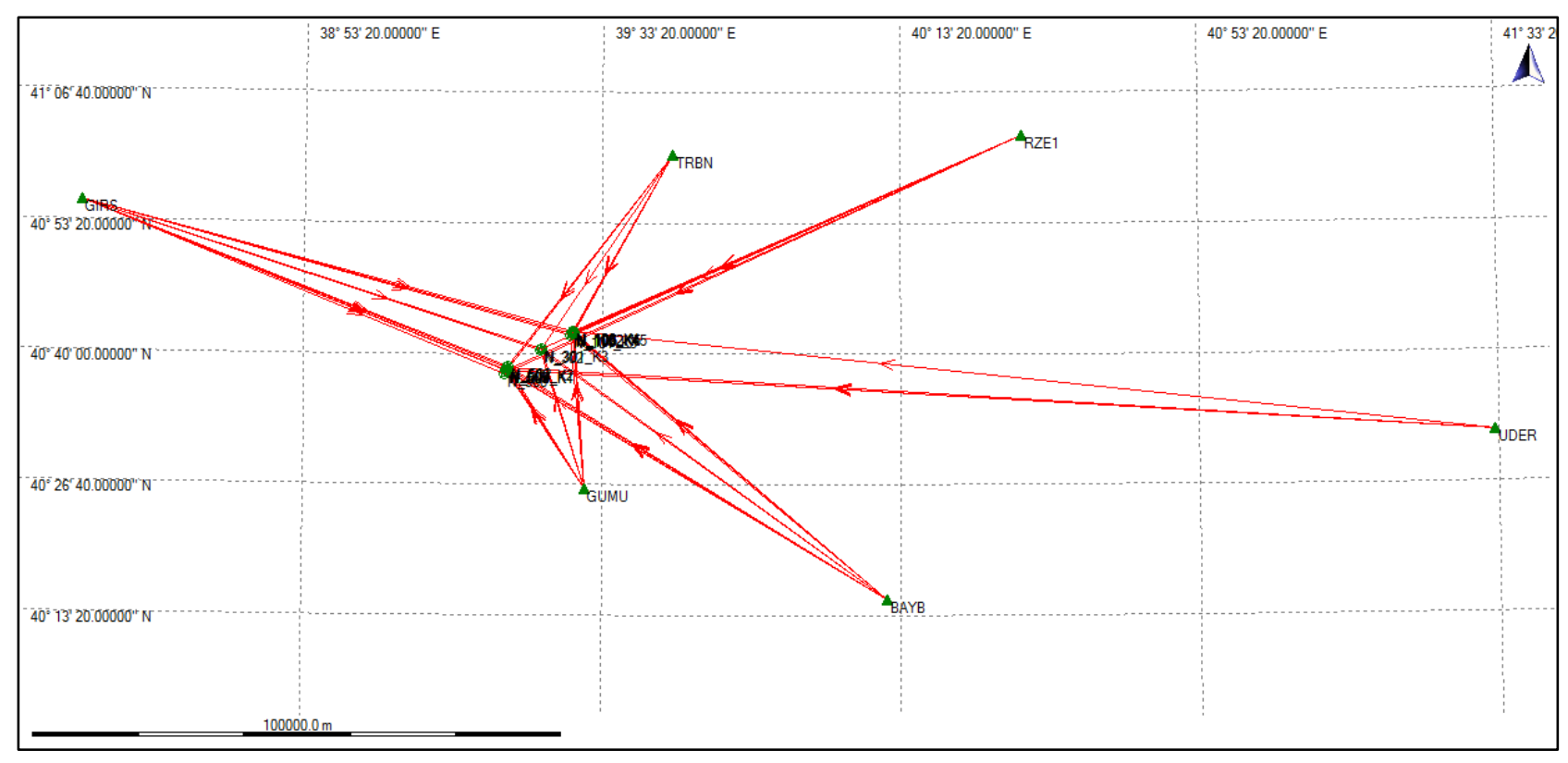

Şekil 4. TUTGA bağlantı noktalarıyla birlikte YZT projesi yatay kontrol ağı noktaları (Köse, 2018)

Türkiye'de, mühendislik projelerinin planlanması ve araziye uygulanmasinda 2005 yılina kadar 1910 yılında belirlenen uluslararas1 Hayford elipsoidinin esas alındığı ED-50 (European Datum 1950) datumu kullanılmaktaydı. 2005 yılında, 1998 tarihli Büyük Ölçekli Haritaların Yapım Yönetmeliği'nin ihtiyacı karşılamaması üzerine hazırlanan BÖHHBÜY'nin yürürlüğe girmesiyle GRS80 (Geodetic Reference System-1980) elipsoidinin esas alındığ 1 ITRF96 datumu kullanılmaya başlanmıştır. Bununla birlikte, projelerde yer kontrol noktalarının GNSS ölçüleri ile belirlenen elipsoidal yüksekliklerinin ülke yükseklik sistemine dönüştürülmesi için uygun 
doğruluğa sahip jeoit bilgisine ihtiyaç vardır. Mühendislik projelerinde, GNSS ölçüleriyle GRS80 elipsoidinde belirlenen elipsoid yüksekliklerinin ülkemizde kullanılan ortometrik yüksekliklere dönüştürülmesi gerekir. $\mathrm{Bu}$ dönüşüm BÖHHBÜY'nin 41. maddesinde belirtildiği şekilde Türkiye Jeoit'inin (TGyy) kullanılmas1 veya GNSS nivelman jeoidi kullanılarak GNSS nivelmanı uygulanması şeklinde gerçekleştirilir. TGyy, TUDKA99 (Türkiye Ulusal Düşey Kontrol Ağı-1999) ile uyumlandırılmış, yayımlandığı yılın son iki rakamı ile anılan ve Harita Genel Müdürlüğü (HGM) tarafindan yayımlanan güncel Türkiye Jeoit'ini ifade etmektedir. Şekil 5'de ortometrik yükseklik ve elipsoit yüksekliği arasındaki ilişki gösterilmektedir. YZT projesinde, ölçülen yükseklikler ortometrik yüksekliklerdir. Projenin ülke TUDKA99 ağına bağlı olarak yükseklik ölçümlerinin yapılabilmesi için HGM tarafından tesis edilen nivelman noktaları (RS) kullanılmıştır.

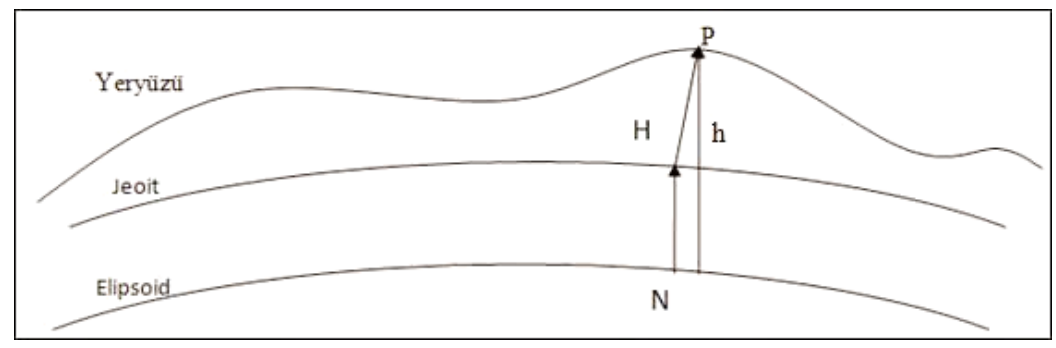

Şekil 5. Orometrik yükseklik ve elipsoit yüksekliği arasındaki ilişki. H: ortometrik yükseklik, h: elipsoit yüksekliği, N: jeoit yüksekliği, P: yeryüzü noktası

BÖHHBÜY'nin 10.maddesine göre, jeodezik çalışmalarda hesaplanacak koordinatlar Transvers Mercator (TM) izdüşümünde üç derecelik dilim esasına göre belirlenir. Transversal konumlu, konform silindirik projeksiyon "Gauss-Krüger projeksiyonu" olarak tanımlanır ve büyük ölçekli harita yapımında yaygın olarak kullanılan bir projeksiyon türüdür. Bu projeksiyonun temelleri, Alman Carl Friedrich Gauss tarafindan atılmış ve Johann Heinrich Louis Krüger tarafindan geliştirilmiştir. Gauss-Krüger projeksiyon sisteminde hesaplanan dik koordinatlara "GaussKrüger koordinatları" denir. Gauss-Krüger koordinatları $\mathrm{Xg}$ ve $\mathrm{Yg}$ olarak gösterilir. $\mathrm{Bu}$ projeksiyon, teğet meridyenden uzaklaştıkça deformasyonların artması nedeniyle, teğet meridyen merkez olmak üzere 3 derecelik dilimlerde uygulanır. $\mathrm{Bu}$ dilim dişına çıkınca silindir 3 derece döndürülüp, takip eden meridyen teğet alınarak projeksiyon yeniden uygulanır. Böylece, her dilimde ayrı koordinat sistemi oluşturulur. Düzlem koordinatlarda ölçek faktörü 1 alınır, yani bozulma olmadığ 1 kabul edilir. Koordinat başlangıç noktasında sağa değerlerde eksi değerlerden kurtulmak için $\mathrm{Y}=500.000 \mathrm{kabul}$ edilir. Universal Transvers Mercator (UTM) projeksiyonu ise Gauss-Krüger projeksiyonu esas alınarak geliştirilmiştir. UTM projeksiyonu, İkinci Dünya Savaşından sonra bütün dünya milletleri için ortak bir harita projeksiyonunun geliştirilmesi düşüncesiyle ortaya atılmış, uygulanacak projeksiyonda doğrultu deformasyonlarının en az olması için açı korurluk, az sayıda projeksiyon yüzeyinin kullanılması, yüzeyler arasında dönüşümlerin mümkün olması, ölçek deformasyonunun belirtilecek sınırlar içinde kalabilmesi, dik koordinat sisteminde beraberliğin sağlanması ve meridyen yakınsamasının 5 dereceden küçük olması şartları aranmıştır. Bu şartların en uyumlu olarak bir arada bulunacağ projeksiyon Gauss-Krüger projeksiyonu olduğu saptanmış, ancak bu projeksiyonda bazı değişiklikler yapılarak sonuçta UTM projeksiyonu ortaya çıkmıştır (Çobanoğlu, 2016). YZT projesinde UTM projeksiyon sistemi kullanılmıştır. Tablo-2'de, YZT projesi nirengi noktalarına ait UTM projeksiyonu koordinatları (sağa ve yukarı değerler), elipsoit koordinatları ve yükseklik değerleriyle birlikte yer almaktadır.

YZT tünel projesi için üretilen koordinatların ve harita altlıklarının farklı koordinat sisteminde üretilmiş harita ve harita bilgileriyle birlikte kullanılabilmesi için koordinat dönüşümüne ihtiyaç vardır. Bunun için, uluslararası Hayford elipsoidine dayal1 olarak ED-50 datumunda üretilen koordinatlar ile GRS80 elipsoidine dayal1 olarak ITRF datumunda üretilen koordinatlar arasinda proje bölgesindeki kadastro müdürlüklerinden temin edilen dönüşüm parametreleri kullanılarak dönüşüm gerçekleştirilmiştir.

YZT için projenin uygulanması öncesinde, harita mühendisliği alanındaki teknik işlerinin son faaliyeti, hâlihazır haritanın üretilmesi işidir. Başta belediyelerin yapacağı teknik hizmetler olmak üzere her türlü projenin planlamas1, 
tasarımı ve uygulaması amaciyla yapılan veya yaptırılan büyük ölçekli haritalara hâlihazır harita denir. Hâlihazır harita üretim çalışmaları BÖHHBÜY'ne göre, TUTGA'ya dayalı olarak ITRF-96 sisteminde gerçekleştirilmiştir. Yersel ölçme çalışmalarında elektronik açı ve mesafe ölçer ölçü aletleri kullanılmıştır. Arazinin topoğrafik durumunun belirlenebilmesi için lüzumlu desen ve karakteristik noktalar ölçülerek eş yükselti eğrileri 1 metre aralığında geçirilmiştir. Ağaçlık alanlar ile az ağaçlıklı ve açık alan sınırları harita üzerinde gösterilmiştir. Elektronik açı ve mesafe ölçer ölçü aletleri yanında TUSAGA-Aktif (Türkiye Ulusal Sabit GNSS Ağı-Aktif Gerçek Zamanlı Kinematik
(GZK) hizmeti veren GNSS Ağı) sistemi kullanılmıştır. $\mathrm{Bu}$ sistem ağ prensibinde çalışan gerçek zamanlı kinematik sabit GNSS istasyonları kullanılarak hücresel dönüşüm parametrelerinin belirlenmesi esasına dayanmaktadır. Bu sayede, TUSAGA-Aktif, kullanıcılara düzeltilmiş konum bilgisini anlık olarak sağlayarak yersel ölçmelerde arazide hızlı, ekonomik ve doğru olarak verilerin toplanmasını olanaklı hale getirir. YZT projesi için halihazır harita üretiminde ağırlıklı olarak TUSAGA-Aktif kullanılmış, topoğrafyanın uydu sinyalinin GNSS alıcısı antenine ulaşmasına imkan vermediği durumlarda ölçmeler elektronik açı ve mesafe ölçer ölçme aletleri ile tamamlanmıştır.

Tablo 2. YZT nirengi noktaları elipsoit ve UTM koordinatları ile yükseklikleri (Köse, 2018)

\begin{tabular}{lllllll}
\hline Nokta No & X & Y & Elip. yük. (h) & Orto. yük. (H) & Sağa Değer & Yukarı Değer \\
\hline N_101 & 3738042.1353 & 3079757.0477 & 1182.8972 & 1152.9768 & 540087.59 & 4507289.75 \\
N_102 & 3737602.6845 & 3079798.7594 & 1146.6662 & 1116.7361 & 541296.75 & 4507728.69 \\
N_103 & 3737687.5122 & 3079945.5899 & 1064.5116 & 1034.5272 & 541358.00 & 4507389.99 \\
N_104 & 3737611.9855 & 3080019.9095 & 1073.6093 & 1043.6504 & 541463.21 & 4507418.06 \\
N_105 & 3737341.5383 & 3079962.0027 & 1061.7099 & 1031.7970 & 541588.47 & 4507781.39 \\
N_106 & 3737418.7970 & 3079856.6051 & 1189.5871 & 1159.6903 & 541457.13 & 4507940.64 \\
N_301 & 3743258.4091 & 3076874.4005 & 1670.4995 & 1640.2703 & 535462.76 & 4504460.45 \\
N_302 & 3743414.2528 & 3076874.9389 & 1683.4784 & 1653.2676 & 535365.05 & 4504289.88 \\
N_502 & 3748650.7597 & 3073290.8392 & 1400.9051 & 1370.5890 & 529286.98 & 4501213.37 \\
N_503 & 3748990.0019 & 3073162.8690 & 1376.4447 & 1346.0850 & 528974.21 & 4500905.49 \\
N_504 & 3749180.4850 & 3073264.8050 & 1233.4032 & 1203.0453 & 528934.21 & 4500413.37 \\
N_505 & 3749207.9660 & 3073182.6910 & 1241.4236 & 1211.0323 & 528853.08 & 4500469.68 \\
N_506 & 3749118.0430 & 3073340.0950 & 1221.0461 & 1190.6717 & 529032.06 & 4500400.21 \\
N_507 & 3749071.3210 & 3073323.4740 & 1241.3183 & 1210.9635 & 529048.45 & 4500495.54 \\
N_508 & 3749707.5894 & 3073193.2967 & 1239.1769 & 1208.7338 & 528546.96 & 4499862.32 \\
N1002 & 3737576.1901 & 3079858.9758 & 1082.4806 & 1052.5442 & 541360.63 & 4507627.07 \\
\hline
\end{tabular}

\section{YZT Projesi Hukuki İşleri}

YZT projesi için kamulaştırma planının hazırlanması amacıyla kamulaştırma sınırları belirlenir. Bunun için, proje ilgili Kadastro Müdürlüğü'nden alınan kadastro haritası ile birleştirilerek projenin isabet ettiği taşınmazların mülkiyet durumu (özel mülkiyet, orman, mera, tescil harici gibi) belirlenir. Sadece proje güzergâhı değil, ileride ihtiyaç duyulabilecek alanlar da kamulaştırma sınırına dâhil edilir. Ayrıca, taşınmazların kamulaştırmadan arta kalan kısımları geometrik olarak kullanılmaya elverişli değilse, bu kısımlar da kamulaştırma sınırları içine alınır. Kamulaştırma sınırlarının son şekline karar verdikten sonra, taşınmazların mülkiyet sınırlarının ve yüzölçümlerinin doğruluğu kadastro yerel birimi tarafindan kontrol edilir.
Kontrol işleminin ardından KGM'ne gönderilen kamulaştırma planı için Kamu Yararı Kararı (KYK) alınır. Hukuki olarak, KYK alındıktan sonra kamulaştırma işlemlerine başlanabilir. Şekil 6'da, YZT Başarköy köyü kamulaştırma planı gösterilmektedir.

Anayasa'nın 46.maddesinde, devlet ve kamu tüzel kişilerinin kamu yararının gerektirdiği hallerde, gerçek karşılıklarını peşin ödemek şartıyla, özel mülkiyette bulunan taşınmaz malların tamamını veya bir kısmını, kanunla gösterilen esas ve usullere göre kamulaştırmaya ve bunlar üzerinde idarî irtifaklar kurmaya yetkili oldukları ifade edilmektedir. KGM tarafindan kamu yararı kararı verildikten sonra özel mülkiyete konu taşınmazların tapu kayıtlarına şerh koyma işlemi gerçekleştirilir. Bir tünel projesi olması nedeniyle 
YZT projesi ağırlıklı olarak yer altındaki mekânı kullanmaktadır. Kamulaştırma ve irtifak hakkı tesisi gerektiren taşınmazlar ise tünelin giriş ve çıkış kısmında bulunmaktadır. YZT projesi nedeniyle artık kullanılamayacak ve mülkiyeti tamamen kamuya geçecek olan taşınamazlar için kamulaştırma, kısmen kullanılabilecek ve YZT projesi nedeniyle kullanımında bir kısitlama olacak taşınmazlar için ise irtifak (kısmen) kamulaştırması gerçekleştirilir. YZT projesi için gerekli olan mekânın mülkiyet hakkının elde edilmesinde kamulaştırma ve irtifak hakkı tesisi dışında üçüncü bir durum ise taşınmazlar üzerinde herhangi bir hak tesisi yapılmadan taşınmaz maliklerinin yeraltından geçen tünele riza göstermesidir. $\mathrm{Bu}$ durumun yasal dayanağı, 2014 y1lında kabul edilen yasa ile Kamulaştırma Kanunu'nun dördüncü maddesinde yapılan düzenlemedir. $\mathrm{Bu}$ düzenlemeye göre, mülkiyet hakkının kullanımının engellenmemesi, can ve mal güvenliği bakımından gerekli önlemlerin alınması kaydıyla, taşınmazların üstünde teleferik ve benzeri ulaşım hatları ile her türlü köprü, taşınmazların altında metro ve benzeri raylı taşıma sistemleri yapılabilmektedir. Kamulaştırma çalışmalarında özel mülkiyete konu taşınmazlar dışında projenin isabet ettiği diğer taşınmazlar için de izin/tahsis işlemlerinin gerçekleştirilmesi gerekir. Örneğin, projenin mera veya orman alanlarını etkilemesi durumunda Tarım ve Orman Bakanlığı, tescil harici yerler için Kamulaştırma Kanunu'nun 30.maddesine göre ilgili idare ve hazine arazileri için Milli Emlak Genel Müdürlüğü ile izin/tahsis işlemleri gerçekleştirilir. Bunun dişında, projeden etkilenen özel mülkiyete konu taşınmazların tarım arazisi olması durumunda bu taşınmazların tarım dışı amaçla kullanılabilmesi için Toprak Koruma ve Arazi Kullanımı Kanunu'na göre, Tarım Reformu Genel Müdürlüğü onayı gereklidir. Son olarak, projenin planlı alanlardan geçmesi durumunda, KYK alınmasından sonra kamulaştırmayı yapan idarenin başvurusu ve ilgili Belediye Encümeni kararıyla plan tadilatı gerçekleştirilerek proje imar planına işlenir.

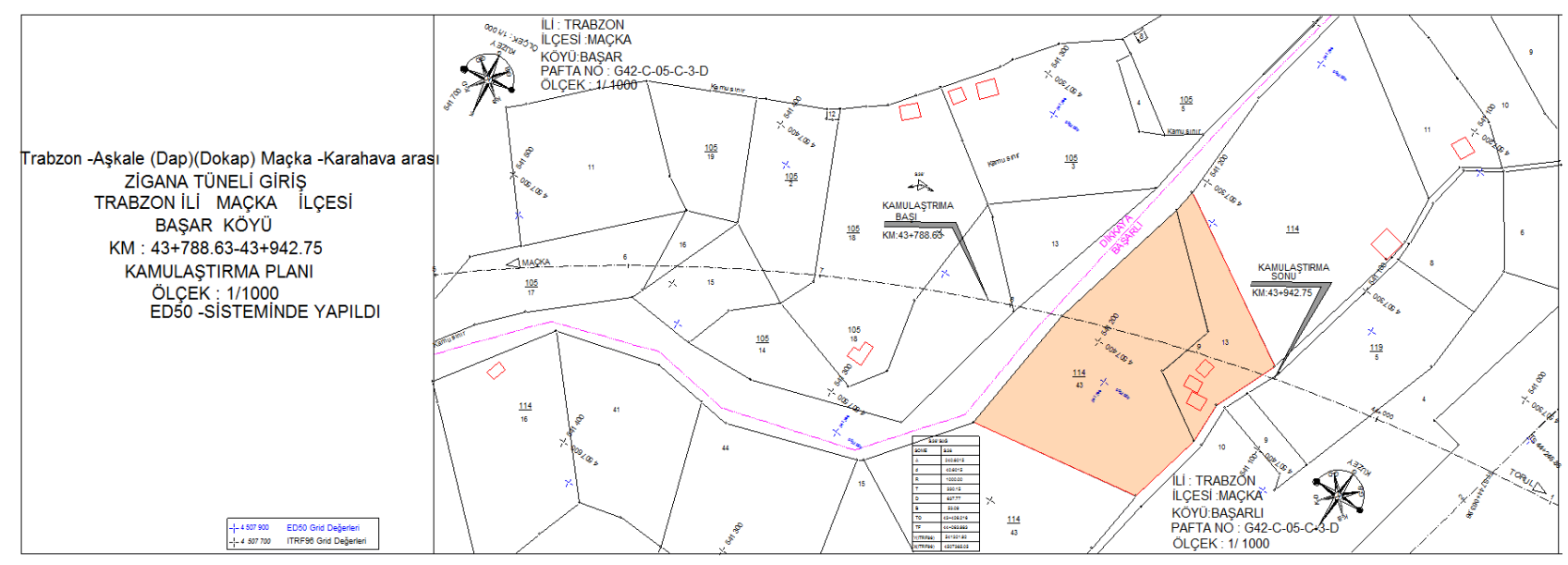

Şekil 6. YZT projesi Başarköy mevki kamulaştırma planı (Köse, 2018).

Gerekli izin/tahsis işlemleri sonrasında varsa proje alanıyla ilgili olarak diğer kurumların görüş ve önerileri dikkate alınarak kesin kamulaştırma planı hazırlanır. Kamulaştırmanın izin/tahsis işlemleri sonraya bırakılarak devam ettirildiği bir süreç, Kamulaştırma Kanunu'nun 27.maddesi dayanak alınarak mümkündür. Kanunda, acele kamulaştırma olarak adlandırılan bu yönteme yurt savunması ihtiyacının gerekli kılması, aceleliğine Cumhurbaşkanınca karar alınacak hallerin bulunması ve özel kanunlarla öngörülen olağanüstü durumların olması halinde başvurulabilir. YZT için acele kamulaştırma gerçekleştirilmemiştir.

Taşınmaz maliklerine ödenecek kamulaştırma bedelinin belirlenmesinin amaçlandığı taşınmaz değerleme faaliyetleri, kamulaştırmay1 gerçekleştiren idare bünyesinde üç kişiden oluşan bir kiymet takdir komisyonunun kurulasıly başlamaktadır. Kamulaştırma Kanunu'nun 8.maddesine göre oluşturulan bu komisyon uzman kişi, kurum ya da kuruluşlardan varsa ticaret odalarından ve mahalli emlak bürolarından rapor veya bilgi alarak taşınmaz değerleme çalışmasının altyapısını oluşturur. Daha sonra, Kamulaştırma Kanunu'nun 11.maddesinde belirtilen kriterler dikkate alınarak kamulaştırılacak taşınmazların değerlerini belirleyen bir rapor komisyon tarafından hazırlanır. Raporda dikkate alınan değer kriterleri taşınmazın cinsi, yüzölçümü, kıymetine etki edebilecek nitelikleri, vergi beyanı, daha önce yapılmış kıymet takdirleri, net geliri, 
arsalarda emsal satı̧̧ değeri, yapılarda birim fiyatları ve maliyetleri kapsamaktadır.

Kıymet takdir çalışmalarının ardından KGM bünyesinde kurulan Uzlaşma Komisyonu ile taşınmaz malikleri arasında uzlaşma görüşmelerinin yapılabilmesi için maliklerin Merkezi Nüfus İdaresi Sistemi (MERNISS)'e kayıtlı adreslerine Pazarlığa Çağrı Bildirimleri (PÇB) gönderilmiştir. PÇB'nde taşınmazla ilgili bilgiler, taşınmazın kamulaştırılacak yüzölçümü, uzlaşma görüşmelerinin yer ve tarihine ilişkin bilgiler bulunmakta, kamulaştırma bedeline ilişskin bilgi ise bulunmamaktadır. Ayrıca, uzlaşma görüşmelerine katılım sağlanmaması durumunda ilgili kanuna göre işlem yapılacağı belirtilmektedir.

Uzlaşma görüşmeleri sonucunda, uzlaşmaya varılan taşınmazlar için taşınamaz sahibi ve uzlaşma komisyonu üyelerinin imzaladığı satın alma tutanağı hazırlanır. $\mathrm{Bu}$ tutanak tescil işleminin hukuki dayanağını oluşturacağından ilgili taşınmaz, malik ve ödenecek bedele ilişkin ayrıntılı bilgi içermektedir. Uzlaşma sağlanan taşınmazlar için hazırlanan tutanaklar tescil işlemleri yapılmak üzere Tapu Sicil Müdürlügü’ne gönderilir. Uzlaşllamayan durumlarda anlaşmazlık tutanağ 1 düzenlenerek taraflarca imzalanır. Ayrıca, tebligat ulaşıp görüşmeye katılmayan veya görüşmeye katılıp anlaşmazlık tutanağını imzalamayan taşınmaz sahipleri için imtina tutanağı düzenlenir. Uzlaşma sağlanamayan taşınmazlar için kamulaştırmayı yapan idare taşınmazın bulunduğu yerin bağlı olduğu Asliye Hukuk Mahkemesi'ne müracaat ederek kamulaştırmaya yönelik bedel tespitini ve idareleri adına tescilini talep eder.

Yer altından geçirilen bir tünel projesi olması nedeniyle, YZT projesinde kamulaştırılan veya irtifak hakkı tesis edilen taşınmaz sayısı arazi üzerinde gerçekleştirilen diğer şeritvari projelerle karşılaştırıldığında oldukça küçüktür. YZT projesinde kamulaştırılan ve irtifak hakkı tesis edilen taşınmazlar parsel niteliğinde olup bunların sayıları sırasıyla 6 ve 9 dur. Kamulaştırılan 6 parselin toplam malik sayıs 30 olurken, irtifak hakkı tesis edilen 9 parselin hisse sayıs 13 olarak belirlenmiştir. Toplam kamulaştırma ve irtifak hakkı yüzölçümleri ise sırasıyla $13809.46 \mathrm{~m}^{2}$ ve $2898.59 \mathrm{~m}^{2}$ olarak gerçekleşmiştir.

\section{Tartışma ve Sonuçlar}

$\mathrm{Bu}$ çalışmada, YZT projesindeki harita mühendisliği uygulamaları teknik ve hukuki işler olmak üzere iki bölüme ayrılarak incelenmiştir. YZT projesinin inşaat aşaması öncesindeki harita mühendisliği alanını ilgilendiren teknik işleri yer kontrol noktaları tesisi, jeodezik referans sistemi seçimi, yükseklik sistemi ve jeoit modeli seçimi, harita projeksiyonu seçimi, koordinat dönüşümü ve halihazır harita üretimi olarak gruplandırılarak ele alınmıştır. Gelişen ölçme teknoloji sayesinde yersel ve uydu bazlı teknikler kullanılarak tünel projesinin uygulanması için ihtiyaç duyulan harita bilgileri üretilebilmiştir. Yoğun bitki örtüsü ve elverişsiz topografya şartları zaman zaman GNSS kullanımını engellemiştir. GNSS ile belirlenen elipsoit yükseklikleri yanında, geometrik nivelman ile ortometrik yükseklikler de belirlenmiştir. Farklı ölçme teknikleriyle elde edilen konumsal veriler, projede kapsamında birlikte kullanılırken, her bir ölçme tekniğinin farklı konumsal doğruluğa sahip olduğu dikkate alınmalıdır. Örneğin, tünel projesi için tesis edilen jeodezik ağın nokta konumlarının belirlenmesinde kullanılan GNSS ile $\pm 1-3 \mathrm{~mm}$ doğrulukta konum belirlemek mümkündür. Bunun yanında, nokta yüksekliklerinin geometrik nivelman ile belirlenmesi durumunda elde edilebilecek konumsal doğruluk $\pm 1 \mathrm{~mm}$ ile $\pm 10 \quad \mathrm{~mm}$ arasındadır. Trigonometrik yükseklik yönteminden yararlanılması durumunda ise konumsal doğruluk $\pm 1-10 \quad \mathrm{~cm}$ arasinda değişebilmektedir. YZT projesinde, tünel giriş ve çıkış bölgesinin hâlihazır haritasını elde etmek için, fotogrametrik yöntemle üretilen orotofoto haritaların konumsal doğruluğu $\pm 10 \mathrm{~cm}$ civarındadır.

YZT projesindeki hukuki işler ise kamulaştırma ve taşınmaz değerleme faaliyetleri olarak ele alınarak değerlendirilmiştir. Hukuki işlerde karşılaşılan temel problemler ise kamulaştırma çalışmalarının uzun sürmesi ve kıymet takdir komisyonu tarafindan belirlenen, taşınmaz maliklerine ödenecek bedelin çoğu durumda gerçek değeri yansıtmaması nedeniyle maliklerle uzlaşma sağlanamamasıdır. YZT projesi her biri 14.5 kilometre olan toplam 29 kilometre uzunluğundaki çift tünel tüpü ile Türkiye ve Avrupa'nın birinci, dünyanın ikinci en büyük karayolu ulaşım tüneli projesi olarak kabul edilmektedir. Bununla birlikte, arazi üzerinde gerçekleştirilen diğer şeritvari mühendislik projeleriyle karşılaştıııldığında yeraltındaki mekânı kullanan YZT için kamulaştırma ve irtifak hakkı tesisi gerçekleştirilen taşınmaz sayısının oldukça küçük olduğu görülmektedir. YZT için toplamda 15 parsel üzerinde 16708,05 $\mathrm{m}^{2}$ yüzölçümü için kamulaştırma ve irtifak hakkı tesisi gerçekleştirilmiştir. Baser vd. (2019)'da, 
Trabzon kent merkezinden geçen yaklaşık $2 \mathrm{~km}$ uzunluğundaki bir yol projesi için kamulaştırılan parsel sayıs1 185 olarak belirlenirken, Döner ve Kaya, (baskıda), kırsal alanda gerçekleştirilen yaklaşık $4 \mathrm{~km}$ uzunluğundaki bir enerji nakil hattı projesi için kamulaştırılacak parsel sayısı 45 olarak tespit edilmiştir.

Mühendislik projelerinin planlanmasında ve uygulanmasına temel altlık kadastro haritalarıdır. $\mathrm{Bu}$ haritalar projelerin hem teknik hem de hukuki işleri için referans alınmaktadır. Mevcut kadastro sistemlerinde temel birim iki boyutlu kadastro parselidir. İki boyutlu kadastro parsellerini ve bu parseller üzerindeki hakları tescil etmeyi amaçlayan mevcut kadastro sisteminin parsellerin altından veya üstünden geçen nesnelerin (tünel, enerji nakil hattı gibi) de teknik ve hukuki bilgilerini yönetebilecek şekilde üç boyutlu bir yapıya kavuşması projelerin uygulanmasında yaşanan teknik ve hukuki problemleri en aza indirecektir.

\section{Teşekkür}

Bu makale, yüksek lisans tezinden (Köse, 2018) geliştirilerek hazırlanmıştır. Torul ve Maçka Kadastro Müdürlükleri ile Cengiz İnşaat Sanayi ve Ticaret A.Ş.'ne bilgi ve belge sağlayarak çalışmaya katkılarından dolayı teşekkür ederiz.

\section{Kaynaklar}

Ademoğlu, Y. 2008. Modern Tünelcilikte Jeodezik Çalışmaların Yönetimi. Yüksek Lisans Tezi, İstanbul Teknik Üniversitesi, Fen Bilimleri Enstitüsü. İstanbul, 111s.

Ayan, T., Aksoy, A., Deniz, R., Arslan, E., Çelik, R.N., Özşamlı, C., Denli, H., Erol, S. ve Erol, Ö.B., 1999. İstanbul GPS Nirengi Ağı (IGNA) Teknik Raporu: Rap. No. 1997/3882, İstanbul Teknik Üniversitesi İnşaat Fakültesi, İstanbul.

Balc1, E., 2010. Kamulaştırma Maliyetinin İstanbul Ulaşım Yatırımlarına Etkilerinin İncelenmesi. Yüksek Lisans Tezi, Bahçeşehir Üniversitesi, Fen Bilimleri Enstitüsü. İstanbul, 72s.

Baser, V., Uzun, B. ve Yildirim, V. 2019. An Alternative Method for Expropriation for Lanelike Projects in Planned Area: a Case Study From Trabzon in Turkey. Survey Review, 51(365), 147-153.

Besner, J., 2017. Cities Think Underground Underground Space (also) for People. Procedia Engineering, 209, 49-55.
Broere, W., 2016. Urban Underground Space: Solving the Problems of Today's Cities. Tunnelling and Underground Space Technology, 55, 245-248.

Çobanoğlu, S.İ., 2016. Kartografya ve Uygulamaları Ders Notları, Harita Genel Müdürlüğü Matbaas1. Ankara, 232s.

Döner, F. ve Kaya, E., 2020. Enerji Nakil Hatt1 Projelerinin Uygulanmasinda Arazi Mülkiyetinin Kazanılması Sürecinin Değerlendirilmesi. Geomatik Dergisi (Baskıda).

Eren, M., 2014. İki Farklı Yöntemle (NATM-TBM) ile Açılan Bir Tünelde Düşey Deformasyon/Deplasman'ların Belirlenmesi: M5 Metro Örneği. Yüksek Lisans Tezi, Yıldız Teknik Üniversitesi, Fen Bilimleri Enstitüsü. İstanbul, 81s.

Faslak, Y., 2019. Karayolu Tünel İnşaatında Jeodezik Çalışmalar: Honaz Tüneli Örneği. Yüksek Lisans Tezi, Yıldız Teknik Üniversitesi, Fen Bilimleri Enstitüsü. İstanbul, 200s.

Gengeç, N.E., 2010. Tünel Açma Çalışmalarında Yatay Yönlendirme Doğruluğunun Belirlenmesi. Yüksek Lisans Tezi, İstanbul Teknik Üniversitesi, Fen Bilimleri Enstitüsü. İstanbul, $87 \mathrm{~s}$.

HGM, 2020. Harita Genel Müdürlüğü, Türkiye Ulusal Temel GPS Ağ1 (TUTGA), https://www.harita.gov.tr/ images/jeodezifaaliyetler/d5a4eb6752402a7.pdf

Hiironen, J., Riekkinen, K. ve Tuominen, H., 2015. The Impact of a New Subway Line on Property Values in Helsinki Metropolitan Area, FIG Working Week 2015, May 2015, Sofia, Bulgaria.

Ho, S. ve Rajabifard, A., 2016. Towards 3D-Enabled Urban Land Administration: Strategic Lessons from the BIM Initiative in Singapore. Land Use Policy, 57, 1-10.

Hunt, D.V.L., Nash, D. ve Rogers, C.D.F., 2014. Sustainable Utility Placement via Multi-Utility Tunnels. Tunnelling and Underground Space Technology, 39, 15-26.

Jensen, A.B.O. ve Almholt, A., 2014. Geodetic Infrastructure and Positioning for the Fehmarnbelt Fixed Link, FIG Working Week 2015, May 2015, Sofia, Bulgaria.

Kaliampakos, D., Benardos, A. ve Mavrikos, A., 2016. A Review on the Economics of Underground Space Utilization. Tunnelling and Underground Space Technology, 55, 236-244.

Kalkan, Y., Alkan, R.M. ve Yanalak, M. 2005. Ulaştırma Yapılarına İlişkin Mühendislik 
Projelerinde Yatay-Düşey Kontrol Ağlarının Oluşturulması: Üsküdar-Ümraniye II. Etap Hafif Metro Projesi Örneği, 10. Türkiye Harita Bilimsel ve Teknik Kurultayı, 28 Mart - 1 Nisan 2005, Ankara.

Karataş, K., Demir, O. ve Bıyık, C. 2007. Altyapı Tesislerinin Mülkiyetle İlişkisi: Trabzon Şehir Geçişi Tüneli Örneği, 11. Türkiye Harita Bilimsel ve Teknik Kurultayı, Nisan 2007, Ankara.

KGM, 2019. Karayolları Genel Müdürlüğü, İstatistikler, Köprü ve Tünel Bilgileri, Tünel Envanteri Bilgileri, https://www.kgm.gov.tr/SiteCollectionDocumen ts/KGMdocuments/Istatistikler/KopruveTunelBi lgileri/tunelenvanterbilgileri.pdf.

Köse, E., 2018. Tünel Çalışmalarında Harita Mühendisliği Uygulamaları: Yeni Zigana Tüneli Örneği. Yüksek Lisans Tezi, Gümüşhane Üniversitesi, Fen Bilimleri Enstitüsü. Gümüşhane, 78s.

Lee, A.H.S., 2007. Engineering Survey System for TBM (Tunnel Boring Machine) Tunnel Construction., FIG Working Week 2007, May 2007, Hong Kong SAR, China.

Li, G. ve Huang, S., 2018. Control Survey for a $6.7 \mathrm{~km}$ Immersed Tunnel in Chinese Lingding Ocean, FIG Congress 2018, May 2018, Istanbul, Turkey.

Namlı, M., 2018. Üsküdar-Ümraniye-Çekmeköy Metro Hattında Yapılan Uygulama Değişikliklerinin Projeye Mali ve Süresel Etkisi. Ömer Halisdemir Üniversitesi Mühendislik Bilimleri Dergisi, 7(1), 190-196.

Satır, B., 2007. Tünel Deformasyonlarının Jeodezik, Geoteknik ve Sonlu Eleman Yöntemleri ile Belirlenmesi. Yüksek Lisans Tezi, Karadeniz Teknik Üniversitesi Fen Bilimleri Enstitüsü. Trabzon, 94s.
Seydanlıoğlu, A., 2009. Metro Tünellerinde Deformasyon Ölçmeleri 4.Levent - Ayazağa Metro Hattı Örneği. Yüksek Lisans Tezi, Yıldız Teknik Üniversitesi Fen Bilimleri Enstitüsü. İstanbul, 112s.

Sun, F., Liu, C. ve Zhou, X., 2017. Utilities Tunnel's Finance Design for the Process of Construction and Operation. Tunnelling and Underground Space Technology, 69, 182-186.

Tanrıvermiş, H., Akipek, Ş., Bayramin, İ., Gün, A.S. ve Aliefendioğlu, Y., 2008. Bağbaşı Barajı ve Hidroelektrik Santrali ve Mavi Tünel Projesi Kamulaştırma Alanındaki Arazilerin Gelirleri, Kapitalizasyon Oranları ve Birim Arazi Değerlerinin Araştırılması. Ankara Üniversitesi, Fen Bilimleri Enstitüsü, Taşınmaz Geliştirme Anabilim Dalı Yayın No:2, Ankara.

Ünlütepe, A. ve Messing, M. 2005. Tünel Ölçme Uygulamalarında Son Yenilikler, 2. Mühendislik Ölçmeleri Sempozyumu, Kasım 2005, İstanbul.

Wang, T., Tan, L., Xie, S. ve Ma, B., 2018. Development and Applications of Common Utility Tunnels in China. Tunnelling and Underground Space Technology, 76, 92-106.

Yalçınkaya, M., Satır, B. ve Akköse, M., 2006. Determining the Displacement Occurred in the Tunnels Using Different Measurement and Finite Elements Methods: A Case Study for Trabzon-2 Tunnel, $3^{\text {rd }}$ IAG Symposium, May 2006, Baden, Austria.

Yüceses, O. 2019. Karayolu Tünellerinde Jeodezik ve Jeoteknik Yöntemlerle Deformasyon Analizi. Yüksek Lisans Tezi, Çanakkale Onsekiz Mart Üniversitesi, Fen Bilimleri Enstitüsü. Çanakkale, 255s. 